\title{
Population genetic structure of the red fox (Vulpes vulpes) in the UK
}

\author{
Helen Atterby • Theo R. Allnutt • Alan D. MacNicoll • \\ Eleanor P. Jones • Graham C. Smith
}

Received: 13 August 2014 / Accepted: 23 November 2014 / Published online: 19 December 2014

(C) The Author(s) 2014. This article is published with open access at Springerlink.com

\begin{abstract}
The red fox (Vulpes vulpes) is common and widely distributed within the UK. It is a carrier or potential carrier of numerous zoonotic diseases. Despite this, there are no published reports on the population genetics of foxes in Britain. In this study, we aim to provide an insight into recent historical movement of foxes within Britain, as well as a current assessment of the genetic diversity and gene flow within British populations. We used 14 microsatellite markers to analyse 501 red fox samples originating from England, southern Scotland and northern France. High genetic diversity was evident within the sample set as a whole and limited population genetic structure was present in British samples analysed. Notably, STRUCTURE analysis found support of four population clusters, one of which grouped two southern England sampling areas with the nearby French samples from Calais, indicating recent (post-formation of the Channel) mixing of British and French populations. This may coincide with reports of large-scale translocations of foxes into Britain during the nineteenth century for sport hunting. Other STRUCTURE populations may be related to geographic features or to cultural practices such as fox hunting. In addition, the two British
\end{abstract}

Communicated by: Jan M. Wójcik

Electronic supplementary material The online version of this article (doi:10.1007/s13364-014-0209-6) contains supplementary material, which is available to authorized users.

H. Atterby · T. R. Allnutt • A. D. MacNicoll • E. P. Jones •

G. C. Smith $(\bowtie)$

Food and Environment Research Agency, Sand Hutton,

York YO41 1LZ, UK

e-mail: graham.smith@apha.gsi.gov.uk

T. R. Allnutt

CSIRO Animal, Food and Health Sciences, Melbourne, Australia

G. C. Smith

National Wildlife Management Centre, Animal and Plant Health

Agency, Sand Hutton, York YO41 1LZ, UK urban populations analysed showed some degree of differentiation from their local rural counterparts.

Keywords Red fox · Vulpes vulpes · Microsatellites · Population structure $\cdot$ Great Britain

\section{Introduction}

The red fox (Vulpes vulpes) is a widespread carnivore, occupying much of the Northern Hemisphere in its natural range. It is present throughout mainland Britain, with naturally low densities in upland areas, higher densities in the south and west of England and Wales (Webbon et al. 2004) and a total population size of approximately 240,000 (Harris et al. 1995). In England and Wales, foxes are present in a substantial number of urban areas, and this has recently increased (Scott et al. 2014). The red fox is considered by some to be a pest species, being an opportunistic hunter of game birds, groundnesting birds and small mammals, often killing animals surplus to its needs (Macdonald et al. 1998). In addition, it is a potential carrier of a number of zoonotic diseases, for example classic rabies virus (Wandeler et al. 1974), Echinococcus multilocularis and Trichinella spiralis (Learmount et al. 2012; Zimmer et al. 2008). Within Britain, $62 \%$ of foxes carry Toxocara canis (Smith et al. 2003).

British foxes are thought to have originated from central European populations prior to the formation of the English Channel around 8200 years BP (Edwards et al. 2012) and have apparently undergone genetic divergence since then. However, during the late eighteenth and early nineteenth centuries, it was widely reported that the fox population in Britain had fallen to very low numbers. Estimates of the extent of this population size decay are not accurately reported, as it was based on large numbers of anecdotal reports (Bovill 1959; Carr 1976; MacDonald 1989; Griffin 2008). This decline was 
in part due to the popularity of sport hunting but also the control of foxes by people who were reliant on rabbits and other game for protein in their diet (Lloyd 1980). It is therefore likely that this reduction in red fox numbers was restricted to regional locations, e.g. the South East of England where fox hunting was prevalent. In order to sustain fox hunting practices, foxes were translocated from continental Europe (Griffin 2008). This trade of foxes became quite substantial, with reports of Leadenhall Market in London handling 1000 foxes a year, France being one of the major providers (Bovill 1959). In addition, more regional translocations of foxes were reported from Wales, Scotland and northern England to southern England (Lloyd 1980).

A greater insight and improved understanding of the genetic structure of foxes within Britain and parts of continental Europe would provide an insight into the effects of these recent historical movements on the current British fox population. Microsatellites are a widely used genetic tool for determining the degree of population structure and relatedness of individuals. Population genetic studies using microsatellite markers have been widely reported in mammalian species, e.g. the Eurasian badger (Meles meles) (Pope et al. 2007), red fox (Galov et al. 2014) and the black bear (Ursus americanus) (Brown et al. 2009). Such studies have provided information on the social structure, population dynamics, historical movements and gene flow within the animals sampled. However, despite the long and chequered history of the red fox in the UK, there have been no large-scale published studies using microsatellite analysis to study red fox populations within the British Isles. Teacher et al. (2011) reported a small degree of genetic isolation by distance, in modern mitochondrial control region data, from red fox samples originating in Western Europe. Analysis of ancient red fox remains, in the same study, also indicated a wide-scale absence of phylogeographic structure in Western Europe, based upon cytochrome $b$ data. Edwards et al. (2012) examined mitochondrial cytochrome $b$ and control region sequences from 399 modern and 31 ancient fox tissue samples originating from Europe. These data indicated that red foxes from Britain and mainland Europe were a contiguous population before the formation of the English Channel, but as the land bridge became fully submerged around $8200 \mathrm{BP}$, British foxes became isolated from mainland Europe populations. As a consequence, following the disappearance of this land bridge, the British red fox population is thought to have undergone a founder effect and a separate evolutionary pathway. However, this study does not provide recent historical evidence of the relatedness of British and Mainland Europe red fox populations, which could be determined by microsatellite analysis.

Galov et al. (2014) discovered a low genetic differentiation in red fox populations in Croatia based upon analysis of mitochondrial control region haplotypes, with no restriction on gene flow posed by rivers or small mountains. A small number of country-level studies of red fox population using microsatellites have been undertaken, which have found limited levels of population differentiation. Wandeler et al (2003) found small levels of population differentiation in a study of urban and rural populations of foxes in Zurich, Switzerland, finding that a river barrier contributed to population isolation. Mullins et al. (2014) studied the population genetics of Polish red fox population using nine microsatellite markers and found low genetic differentiation between locations within the country, which they attribute to the high connectivity of the Polish landscape and the high dispersal distances of the foxes. Magory Cohen et al. (2013) found four genetic clusters within populations of red foxes sampled in Israel, indicating that, in certain landscapes, population structure can be detected in this highly vagile species.

This study aims to use analysis of microsatellite fragments to provide an insight into the population genetics of the red fox in Britain and look for evidence of European introductions. This would enable an estimation of the genetic diversity of different clusters/groups and the importance of any physical barriers or low-density areas in restricting movement, which may be of use in studies predicting exotic disease spread in foxes, for example E. multilocularis.

\section{Materials and methods}

\section{Samples}

Red fox tissue samples were obtained via the carcass collection carried out as part of the UK Trichinella surveillance programme (Zimmer et al. 2008). Fox carcasses were collected from gamekeepers and landowners during standard pest control practices, as well as via road traffic accidents. Post-mortem, an ear tip or bicep muscle sample was collected for genetic analysis and stored at $-20{ }^{\circ} \mathrm{C}$. Red fox whole blood and tissue samples were also obtained from individuals in two regions in France (from the French Agency for Food, Environmental \& Occupational Health and Safety (ANSES), Maisons-Alfort, Paris).

Geographical coordinates (latitude and longitude) for all individual fox samples collected were plotted in Arc-GIS 9.3.1 software (Esri, Redlands, CA, USA). Individual fox samples were included in the analysis at locations where relatively high numbers had been sampled. These locations formed the putative populations and individuals were chosen for inclusion so that they covered a wide geographic area of England and Southern Scotland, in discrete clusters (Fig. 1). A 


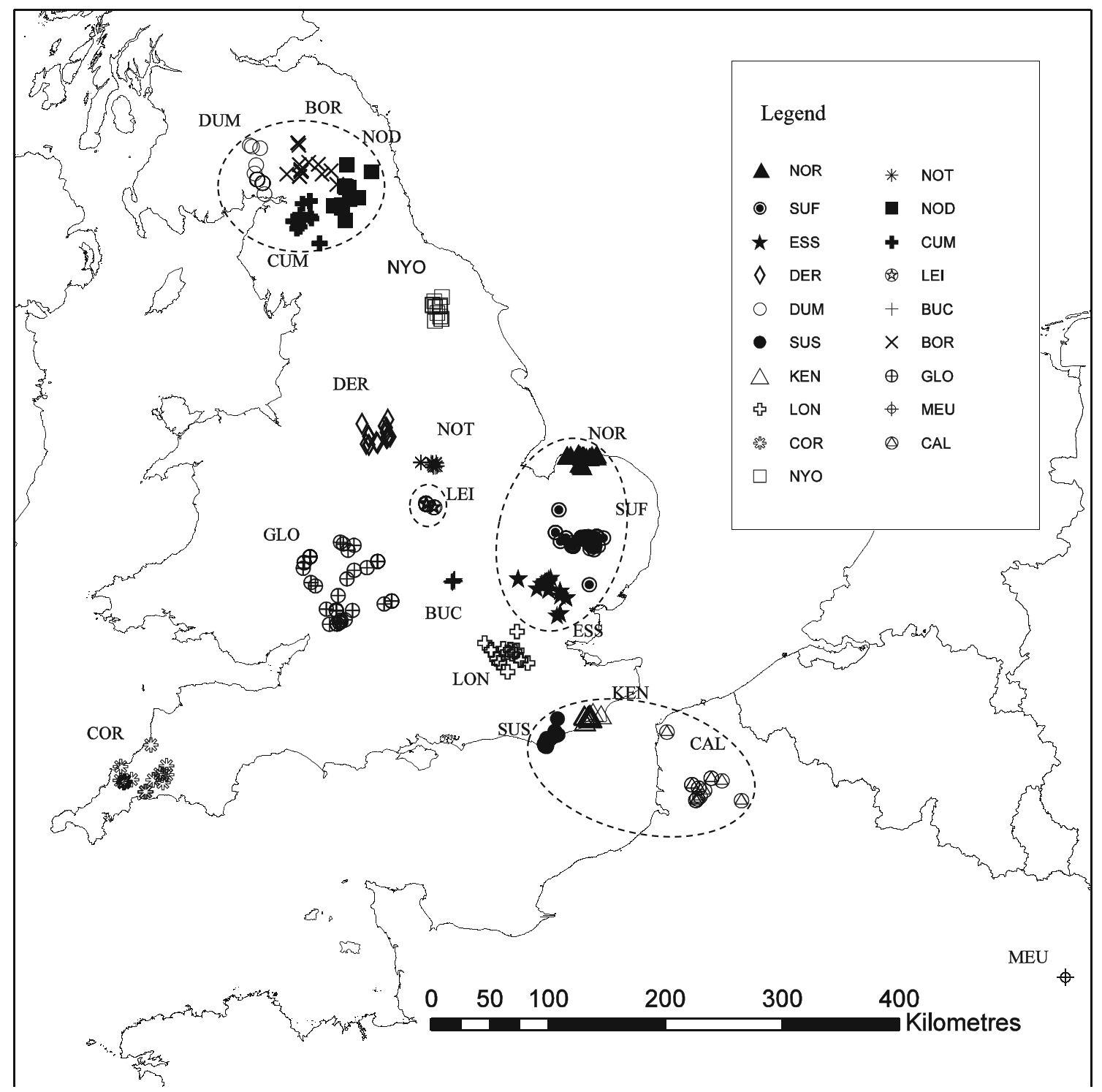

Fig. 1 UK map showing the locations of the putative red fox populations sampled in this study. Overlaid in dashed circles are the four clusters identified in the STRUCTURE Bayesian clustering analysis

range of different land use classes were selected where possible and two urban sites were included.

\section{Genotyping}

DNA was extracted from ear tips or biceps according to a method for rapid isolation of nucleic acids from mammalian tissues (Sambrook and Russell 2001). A piece of tissue weighing approximately $100 \mathrm{mg}$ was excised from the sample. Proteinase $\mathrm{K}$ was then added to induce cell lysis, and the proteins precipitated using $10 \mathrm{M}$ ammonium acetate (SigmaAldrich, Poole, Dorset, UK) (rather than potassium acetate as stated; Sambrook and Russell 2001). DNA was precipitated with isopropanol, the pellet washed in $70 \%$ ethanol and resuspended in $200 \mu$ l of $1 \times$ TE buffer (Sigma-Aldrich, Poole, Dorset, UK). DNA extraction from whole blood samples were carried out using the QIAamp DNA Blood Midi/Maxi Kits (spin protocol) (Qiagen Ltd, Crawley, West Sussex, UK) depending upon the volume of blood collected. In order to prevent blockage of the spin column, a 1 in 10 dilution of the blood sample with phosphate buffered saline was carried out prior to loading on the column.

Amplification of the microsatellite fragments was carried out with 14 loci, as detailed in Table 1. These loci were previously reported as amplifying microsatellites in dog breeds (Ostrander et al. 1993; Holmes et al. 1993, 1995; Francisco et al. 1996; Fredholm and Wintero 1995), $V$. vulpes and Vulpes lagopus (Arctic foxes). The markers were not multiplexed until after the PCR amplification stage, as multiplexed PCRs with these markers and DNA samples were found to substantially compromise microsatellite amplification. PCR reactions comprised $10 \mu \mathrm{l}$ JumpStart REDTaq 


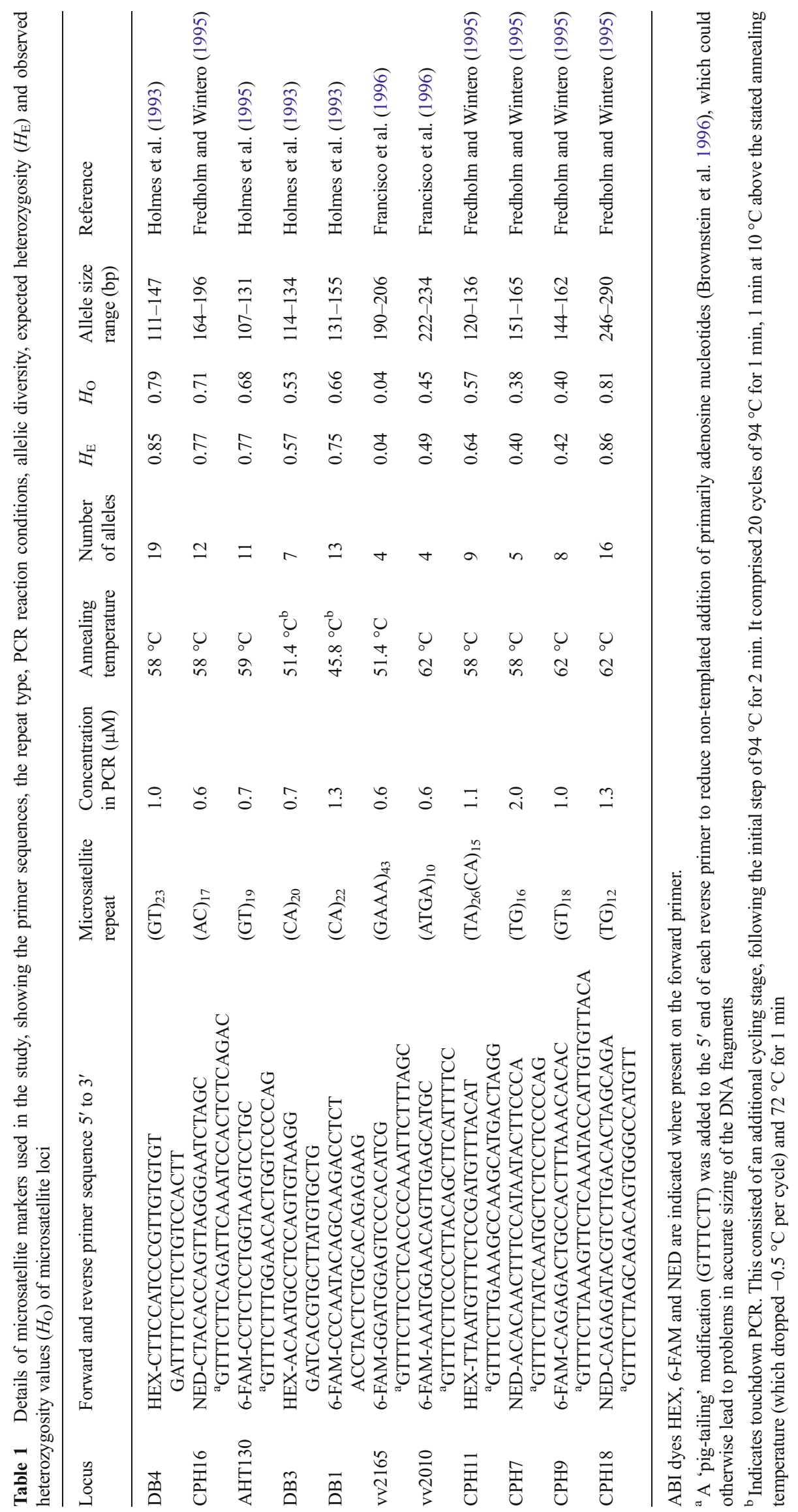


ReadyMix PCR Reaction Mix ( $2 \times$ reaction concentrate) (Sigma-Aldrich) containing $1.5 \mathrm{mM} \mathrm{MgCl}$; forward and reverse primers (concentrations detailed in Table 1) (SigmaAldrich/Applied Biosystems, Foster City, CA, USA); and $1 \mu \mathrm{l}$ DNA template. Magnesium chloride concentrations were $1.5 \mathrm{mM}$ (ABgene, Epsom, Surrey, UK) and the remaining volume was made up to $20 \mu \mathrm{l}$ with de-ionised sterile water. PCR reactions were performed using standard reaction conditions of $94{ }^{\circ} \mathrm{C}$ for $2 \mathrm{~min}, 35$ cycles of $94{ }^{\circ} \mathrm{C}$ for $1 \mathrm{~min}, 1 \mathrm{~min}$ at the annealing temperature (Table 1 ), and $72{ }^{\circ} \mathrm{C}$ for $1 \mathrm{~min}$. This was followed by a final extension of $72{ }^{\circ} \mathrm{C}$ for $5 \mathrm{~min}$ and $60{ }^{\circ} \mathrm{C}$ for $1 \mathrm{~h}$ (some loci required an additional touchdown stage as detailed in Table 1).

Microsatellite fragment analysis was carried out using POP-7 polymer in a $36-\mathrm{cm}$ capillary array, mounted on a 3130xl Genetic Analyser (Applied Biosystems) using Genescan Rox 500 size standard (Applied Biosystems) following standard protocols. Two negative controls were included in each DNA extraction batch, which were then PCR-amplified with all loci and analysed using 3130xl Genetic Analyser. This enabled a thorough assessment of the whole procedure for cross-contamination issues. GENEMAPPER 3.7 (Applied Biosystems) was used to determine the accurate size of each microsatellite fragment.

\section{Data analysis}

Null allele frequency estimates per locus were determined using CERVUS 3.0 (Kalinowski et al 2007). All microsatellites were tested for departures from Hardy Weinberg equilibrium (HWE) and for linkage disequilibrium using GENEPOP (Rousset 2008), using 10,000 dememorisation steps and 1000 batches of 5000 iterations per batch. $P$ values were adjusted for multiple tests using the Bonferroni correction. GENETIX (Belkhir et al. 2004) was used to calculate the overall estimate of $G_{\mathrm{ST}}$ (Nei 1973), expected heterozygosity $\left(H_{\mathrm{E}}\right)$ and observed heterozygosity $\left(H_{\mathrm{O}}\right)$ values per locus and per population, mean number of alleles $(A)$ per population and the inbreeding coefficient $\left(F_{\text {IS }}\right)$ (Weir and Cockerham 1984) per population. GENETIX was also used to visualise the differences between populations using a Factorial Correspondence Analysis (FCA), based on the multilocus genotypes of all the samples. STRUCTURE 2.3.4 (Pritchard et al. 2000) was used to investigate the likelihood of each individual belonging to one of several clusters $(K)$ based on allele frequencies, using Bayesian clustering methodology. The admixture ancestry model with correlated allele frequencies was used, assuming a uniform prior and without any prior population information (locprior $=0$ ). The length of the burn-in period was 10,000 iterations and the number of Markov Chain Monte Carlo repetitions was $1,000,000$. The optimum number of clusters was determined by performing 10 runs at $K=1$ to 19 . Structure Harvester (Earl and VonHoldt 2012) (http://taylor0.biology.ucla.edu/ structureHarvester) was also used to calculate the Delta $K$ (Evanno et al. 2005). Runs for $K=4$ (the optimum number of populations, as estimated by the log likelihood and Delta $K$ ) were combined into a single graphic using the programmes CLUMPP (Jakobsson and Rosenberg 2007) and DISTRUCT (Rosenberg 2004).

ARLEQUIN 3.5.1.2 (Excoffier and Lischer 2010) was used to calculate the proportion of genetic variation between and within populations, using analysis of molecular variance (AMOVA) and calculation of pairwise $F_{\mathrm{ST}}$ indices and the associated $P$ values (significance tested using 1000 replicate bootstrap) for all populations.

The relationship between geographic and genetic distance between populations (isolation by distance) was assessed with a Mantel test of pairwise genetic and geographic distance between individuals in the program GenAlEx v6.501 (Peakall and Smouse 2012), using 999 permutations. This was done on the whole dataset and on the British data alone. GenAlEx v6.501 was also used to run a spatial autocorrelation analysis with a range of distance classes (10-50 km), using 999 permutations and 1000 bootstraps to assess the significance of the results.

\section{Results}

All 14 loci were found to amplify $V$. vulpes microsatellite fragments. There was no evidence of linkage disequilibrium between the microsatellite markers, and no departures from HWE within the loci within each location. Three loci (C213, $\mathrm{CPH} 3$ and $\mathrm{CPH} 8$ ) were estimated to have a high frequency of null alleles and were excluded from the dataset. The expected $\left(H_{\mathrm{E}}\right)$ and observed heterozygosity $\left(H_{\mathrm{O}}\right)$ values per locus for the remaining markers are shown in Table 1 . Both $H_{\mathrm{E}}$ and $H_{\mathrm{O}}$ values for locus vv2165 were very low (0.04), because this marker was almost monomorphic for the dataset. However, it amplified quite rare alleles in some of the individuals sampled and is therefore still informative.

DNA extracts from individuals which showed clear amplification products in 8 or more loci out of 11 were included in the analysis $(n=501)$; see Fig. 1 . The number of foxes per population that were included in the analysis ranged from 14 to 58 individuals (Table 2). All microsatellite markers used in the analysis were polymorphic within this dataset, with 7 out of 11 displaying a high degree of polymorphism ( $\geq 7$ alleles).

Values showing the genetic variability within each putative population (Table 2) indicate that sample sizes for all populations were sufficient to enable reliable population genetics analyses (between 14 and 58 individuals per population). All populations showed relatively high allelic diversity, with the mean number of alleles $(A)$ per population between 3.36 and 
Table 2 Genetic variability within each putative population

\begin{tabular}{|c|c|c|c|c|c|c|}
\hline Population & Population ID & $n$ & $H_{\mathrm{E}}$ & $H_{\mathrm{O}}$ & $A$ & $F_{\text {IS }}(95 \% \mathrm{CI})$ \\
\hline Norfolk & NOR & 40 & 0.56 & 0.54 & 5.82 & $0.050(-0.033-0.100)$ \\
\hline Suffolk & SUF & 58 & 0.59 & 0.59 & 6.00 & $0.016(-0.046-0.059)$ \\
\hline Essex & ESS & 38 & 0.54 & 0.56 & 5.55 & $-0.019(-0.095-0.031)$ \\
\hline Derbyshire & DER & 27 & 0.52 & 0.52 & 5.09 & $0.012(-0.089-0.080)$ \\
\hline Dumfries & DUM & 24 & 0.57 & 0.60 & 4.82 & $-0.029(-0.116-0.019)$ \\
\hline Sussex & SUS & 22 & 0.53 & 0.51 & 4.91 & $0.066(-0.054-0.118)$ \\
\hline Kent & KEN & 28 & 0.56 & 0.57 & 5.55 & $-0.002(-0.088-0.044)$ \\
\hline London & LON & 23 & 0.53 & 0.52 & 5.09 & $0.054(-0.062-0.134)$ \\
\hline Cornwall & $\mathrm{COR}$ & 23 & 0.55 & 0.53 & 5.55 & $0.062(-0.058-0.135)$ \\
\hline North Yorkshire & NYO & 15 & 0.56 & 0.53 & 4.73 & $0.084(-0.040-0.129)$ \\
\hline Nottingham & NOT & 25 & 0.54 & 0.51 & 4.36 & $0.080(-0.035-0.150)$ \\
\hline Northumberland & NOD & 20 & 0.54 & 0.51 & 4.36 & $0.094(-0.051-0.180)$ \\
\hline Cumbria & CUM & 18 & 0.55 & 0.53 & 4.82 & $0.067(-0.062-0.123)$ \\
\hline Leicester & LEI & 24 & 0.59 & 0.55 & 4.45 & $0.078(-0.020-0.135)$ \\
\hline Buckinghamshire & BUC & 26 & 0.48 & 0.45 & 5.09 & $0.082(-0.040-0.168)$ \\
\hline Borders & BOR & 23 & 0.54 & 0.58 & 4.27 & $-0.035(-0.141-0.026)$ \\
\hline Gloucester & GLO & 38 & 0.57 & 0.58 & 6.09 & $0.002(-0.067-0.043)$ \\
\hline Meurthe-et-Moselle & MEU & 14 & 0.66 & 0.70 & 5.73 & $-0.024(-0.175-0.056)$ \\
\hline Calais & CAL & 15 & 0.46 & 0.45 & 3.36 & $0.076(-0.069-0.135)$ \\
\hline
\end{tabular}

Population ID and Population identification relates to its geographical location shown in Fig. $1, n$ sample size per population, $H_{\mathrm{E}}$ expected heterozygotes, $H_{\mathrm{O}}$ observed heterozygotes, $A$ mean number of alleles, $F_{\mathrm{IS}}$ inbreeding coefficient (calculated using 1000 bootstraps) with $95 \% \mathrm{CI}$ (confidence intervals)

6.09 and $H_{\mathrm{O}}$ values for each population between 0.45 and 0.70 . The differences between each $H_{\mathrm{E}}$ and the corresponding $H_{\mathrm{O}}$ value per population were minimal. There was no evidence of significant inbreeding, as measured by $F_{\text {IS }}$, within any of the populations analysed.

Using the original population groupings, the analysis of molecular variance (AMOVA) indicated that $94.81 \%$ of the variation in allele frequencies was the result of variation within individuals within populations, and only $5.24 \%$ was due to variation between populations. Grouping individuals into populations using the STRUCTURE groupings at $K=4$ for the AMOVA analysis, a similarly small degree of variation (4.31\%) was apparent between populations within groups, and an additional $0.92 \%$ of the overall variation was between individuals within populations (Table 3).

The STRUCTURE results suggested a best fit of $K=4$ clusters, both from the highest $\log$ probability of the observed clusters (LnP) and highest Delta $K$ (Evanno et al. 2005) (Electronic Supplementary Fig. S1). These clusters corresponded to an East Anglian cluster (Norfolk, Suffolk and Essex), northern England/southern Scotland (Dumfries, Borders, Northumberland and Cumbria), south eastern England and north eastern France (Sussex, Kent and Calais), and an urban cluster comprising the Leicester population. The remaining populations (Derbyshire, London, Cornwall, North Yorkshire, Nottinghamshire, Buckinghamshire, Gloucestershire

Table 3 Analysis of molecular variance (AMOVA) between and within all putative populations studied

\begin{tabular}{|c|c|c|c|c|}
\hline Source of variation & d.f. & Sum of squares & Variance components & Percentage of variation \\
\hline \multicolumn{5}{|l|}{ AMOVA analysis of the geographic populations } \\
\hline Between populations & 18 & 202.37 & 0.16 & 5.24 \\
\hline Between individuals within populations & 482 & 1393.14 & -0.00 & -0.05 \\
\hline Within individuals & 501 & 1449.50 & 2.89 & 94.81 \\
\hline \multicolumn{5}{|c|}{ AMOVA analysis of groups detected by Structure } \\
\hline Between populations & 3 & 50.76 & 0.10 & 4.31 \\
\hline Between individuals within populations & 306 & 710.41 & 0.022 & 0.92 \\
\hline Within individuals & 310 & 706.00 & 2.27 & 94.77 \\
\hline
\end{tabular}




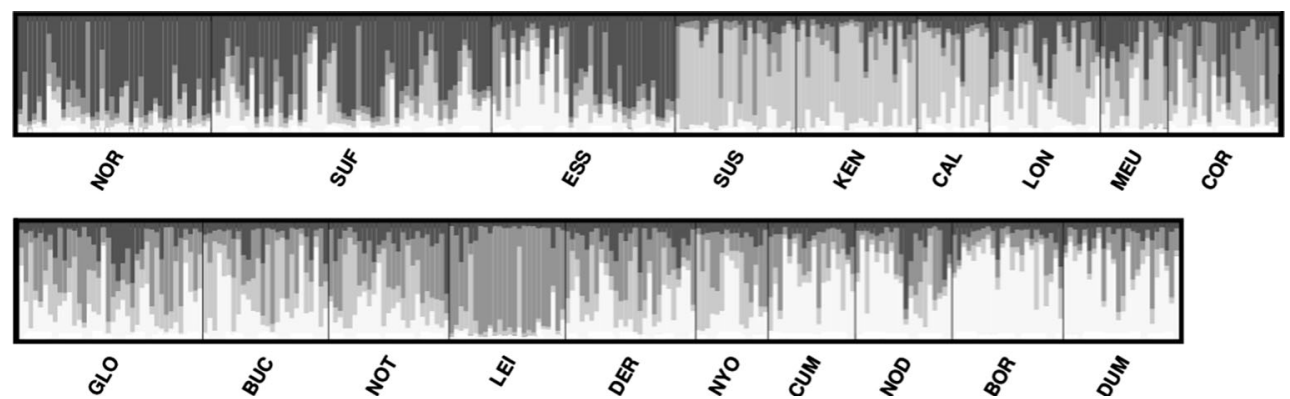

Fig. 2 Visualisation of the Bayesian clustering analysis implemented in STRUCTURE for $K=4$, where each $K$ is shown as a different greyscale shade. Individuals are shown as single vertical bars, grouped by

geographic population; geographic codes (below the plot) are the same as Fig. 1. Data shown are aggregated data from 10 independent runs

and Meurthe-et-Moselle in northern France) did not allocate clearly to any particular population (Figs. 1 and 2). At higher levels of $K$, Calais was identified as a distinct population (at $K=$ 5 ) as was the Meurthe population (at $K=6$; Electronic Supplementary Fig. S3). The FCA found some support for similar clusters and some distinct populations, with the first axis (22.1\% of the total variation) and second axis (20.2\%) of variation separating the East Anglian cluster, the south eastern England and north eastern France cluster, and the Meurthe-etMoselle population, and the third $(19.5 \%)$ and fourth axis (14.0\%) separating out the London population and the northern England/southern Scotland cluster (Electonic Supplementary Fig. S2). None of the first four axes separated the Leicester population as distinct.

The majority of pairwise $F_{\mathrm{ST}}$ values were significant ( $P>0.05$, ranging from 0.004 to 0.181 ), with non-significant values mostly present between pairwise comparisons within the northern England/southern Scotland populations (Northumberland, Cumbria, Borders, Dumfries and North Yorkshire) (Table 4). Both the urban populations (London and Leicester) had high $F_{\mathrm{ST}}$ values in all pairwise comparisons. In contrast to the STRUCTURE analysis, high $F_{\mathrm{ST}}$ values were found between the Calais population and all British populations.

A very small degree of genetic isolation by distance was observed in a positive Mantel test between pairwise geographic and genetic distances, both for the whole dataset $\left(R^{2}=\right.$ $0.0153, P<0.001)$ and for the British data alone $\left(R^{2}=0.007\right.$, $P<0.001)$. The spatial autocorrelation analysis showed a pattern of decreasing relatedness with increasing geographic distance, with significantly positive relatedness values, $r$, among samples that were separated up to around $90 \mathrm{~km}$ (Electronic Supplementary Fig. S4).

\section{Discussion}

Overall, the red fox populations in this study had high levels of microsatellite diversity, similar to those found in other fox microsatellite studies (Wandeler et al. 2003; Oishi et al. 2011;
Magory Cohen et al. 2013; Mullins et al. 2014) and a Random Amplified Polymorphic DNA (RAPD) marker study in northern France (Gachot-Neveu et al. 2009). Pairwise $F_{S T}$ values for all populations indicated a high proportion of mixing among populations, with only slight/moderate genetic differentiation discernible via microsatellite analysis. Further support for this is evidenced by the very high proportion of variation within individuals between populations (95\%), rather than the variation found between populations $(5 \%)$. This pattern of a very high proportion of intra-populational variation was also observed in other red fox populations, for example in Croatia (Galov et al. 2014, with $93 \%$ of the genetic variance being intra-populational) and in Israel (Magory Cohen et al. 2013). All regions of Britain which have been represented in this study therefore appear to have red fox populations which have not experienced a significant bottleneck, with no evidence of substantial restrictions to gene flow. This is perhaps surprising, given the reported extent of the regional fox population decline in the UK during the late eighteenth and early nineteenth centuries, and the likelihood that a proportion of British foxes from this period were derived from imports from the continent. The translocated foxes may have had poor opportunities to breed, given that they were introduced to be hunted. This local population reduction and subsequent translocation do not appear to have had a discernible effect on the genetic diversity of the current population. Other widespread vagile carnivore species show similar trends (i.e. low population differentiation and high genetic diversity), such as the golden jackal (Magory Cohen et al. 2013), wolverine (Kyle and Strobeck 2002) and American pine marten (Kyle and Strobeck 2003).

Despite low levels of between-group variation, the Bayesian clustering analysis in STRUCTURE still found highest support for four genetic groupings of fox populations. Some of these clusters were also apparent in the Factorial Correspondence Analysis (FCA). These findings were in contrast to the fox microsatellite study in North East Poland (Mullins et al. 2014), which found no population substructuring, but similar to those in Israel (Magory Cohen et al. 2013), which also identified four genetic subpopulations. This is likely an effect 


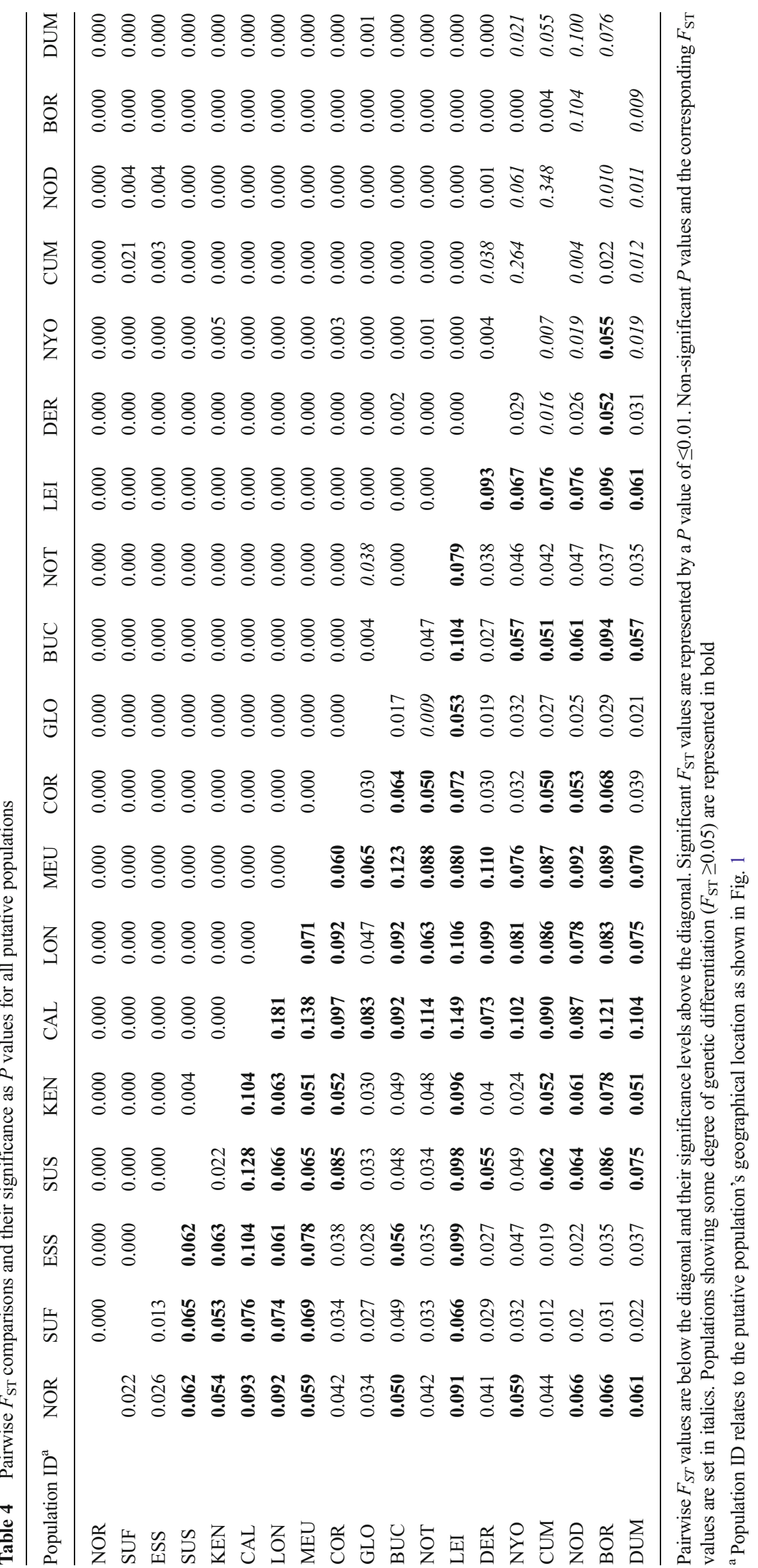


of weaker landscape connectivity for foxes in Great Britain and Israel, which have relatively heterogeneous landscapes, compared to the area in the Polish study, which has few large urban areas and is characterised by mixed woodland and agriculture, with greater landscape connectivity. Factors affecting fox density and thus genetic diversity and gene flow include landscape variables, availability of resources and intense culling practices (Heydon and Reynolds 2000; Heydon et al. 2000). At the wider geographic scale, Edwards et al. (2012) reported evidence of segregation of populations of red foxes within Europe based upon mitochondrial DNA (cytochrome $b$ and control region) analysis, in particular England, Scotland, Wales, Ireland and the Netherlands formed one population and the rest of Europe another.

Some of the STRUCTURE clusters could be identified clearly, while a large proportion of the populations and individuals were admixed, supporting the interpretation of weak population subdivisions within the data. The FCA and pairwise $F_{\text {ST }}$ values did provide some additional support, notably for the East Anglian cluster (Norfolk, Suffolk and Essex), which is isolated on two sides by the North Sea and an area that has historically been characterised by high levels of fox hunting, and a northern England/southern Scotland cluster, which may be relatively isolated from the rest of the populations sampled by the high ground in the north of England. The two primarily urban populations, London and Leicester, both show some degree of distinctiveness from other populations in certain analyses; Leicester is identified as a distinct cluster in STRUCTURE but not the FCA, London shows some degree of separation from other populations in the FCA but not STRUCTURE, and both have high pairwise $F_{\mathrm{ST}}$ values with other populations. They are relatively distinct from the British rural populations, which implies that gene flow between urban and rural communities may be somewhat restricted. The lack of any apparent difference between the range of observed heterozygosity levels found in rural (0.42 to 0.64) when compared to urban sites ( 0.46 and 0.50$)$ indicates that the two urban sites studied did not have any founder effect(s) or subsequent genetic drift. These findings are in contrast to the origins of the urban population of red foxes reported in the city of Zurich (Wandeler et al. 2003). However, it is suggested that the likely founder effects observed in the Swiss study could at least in part be due to the dramatic rise in fox density, which occurred following the cessation of a culling programme carried out during the 1970s and 1980s, in response to the continental rabies epidemic (Gloor et al. 2001). Given its relative isolation within Britain, and its distance from other sampling locations, it is surprising that the Cornish population shows no significant genetic isolation from the other populations. Both the FCA and the STRUCTURE analysis support a south eastern England/ north eastern France cluster of Kent, Sussex and Calais. At higher values of $K$, the Calais population becomes a distinct population in the STRUCTURE analysis. However, the pairwise $F_{\mathrm{ST}}$ values between Sussex/
Kent and Calais are higher than many other pairwise values. This discrepancy aside, the clustering of these populations supports the recent mixing of these French and English populations, possibly due to the translocation of French foxes into a declining English fox population in this area of England during the nineteenth century (Bovill 1959; Griffin 2008).

The significantly positive relatedness values among individuals up to around $90 \mathrm{~km}$, as detected by the spatial autocorrelation analysis, show that individuals within this distance were more likely to be related to each other than would be expected by chance. The extent of this distance may be caused by relatively higher dispersal in British foxes. This distance compares with a value of approximately $20 \mathrm{~km}$ found in Poland (Mullins et al. 2014). We also found small but statistically significant genetic isolation by distance, which is likely to be the result of random genetic drift. These findings are consistent with those of Teacher et al. (2011), who report a small degree of genetic isolation by distance, in modern mitochondrial control region data, and a wide-scale absence of phylogeographic structure (using ancient samples) based upon cytochrome $b$ data, in $V$. vulpes in Western Europe. The species' versatility and capacity to adapt to a broad range of habitats, along with a comparatively high degree of dispersal in both males and females, are suggested as the main reasons for the low levels of genetic structure observed (Teacher et al. 2011).

In conclusion, this study has found high genetic diversity and low phylogeographic structure within England and southern Scotland with a limited degree of isolation by distance, perhaps caused by human translocations of foxes or a naturally high migration rate. Urban fox populations may only be slightly differentiated from the local rural populations. One French population was found to be similar to south eastern England populations, indicating that there has been some relatively recent gene flow between the populations, potentially a residual genetic impact from nineteenth century importation of foxes into areas of low population density within Britain. This also suggests that there are no substantial barriers to exotic disease spread within foxes in Britain.

Acknowledgments The authors would like to acknowledge the Animal Health and Welfare division of the Department for Environment Food \& Rural Affairs for funding this study. The authors would also like to thank Florence Cliquet, Gérald Umhang, Céline Richomme, Benoît Combes and Franck Boue for kindly providing us with red fox blood and tissue samples from locations in France. In addition, we would also like to thank Alba Hernandez for her invaluable help in cataloguing the samples.

Open Access This article is distributed under the terms of the Creative Commons Attribution License which permits any use, distribution, and reproduction in any medium, provided the original author(s) and the source are credited. 


\section{References}

Belkhir K, Borsa P, Chikhi L, Raufaste N, Bonhomme F (2004) GENETIX 4.05, Windows TM software for population genetics. Laboratoire Génome et Populations, Université de Montpellier, Montpellier, France

Bovill EW (1959) The England of Nimrod and Surtees 1815-1854. Oxford University Press, Oxford

Brown SK, Hull JM, Updike DR, Fain SR, Ernest HB (2009) Black bear population genetics in California: signatures of population structure, competitive release, and historical translocation. J Mammal 90: 1066-1074

Brownstein MJ, Carpten JD, Smith JR (1996) Modulation of nontemplated nucleotide addition by tag DNA polymerase: primer modifications that facilitate genotyping. Biotechniques 20:1004 1010

Carr R (1976) English fox hunting: a history. Weidenfeld and Nicolson, London

Earl DA, VonHoldt BM (2012) STRUCTURE HARVESTER: a website and program for visualizing STRUCTURE output and implementing the Evanno method. Conserv Genet Resour 4(2):359-361

Edwards CJ, Soulsbury CD, Statham MJ, Ho SYW, Wall D, Dolf G, Iossa G, Baker PJ, Harris S, Sacks BN, Bradley DG (2012) Temporal genetic variation of the red fox, Vulpes vulpes, across western Europe and the British Isles. Quat Sci Rev 57:95-104

Evanno G, Regnaut S, Goudet J (2005) Detecting the number of clusters of individuals using the software STRUCTURE: a simulation study. Mol Ecol 14:2611-2620

Excoffier L, Lischer HEL (2010) Arlequin suite ver 3.5: a new series of programs to perform population genetics analyses under Linux and Windows. Mol Ecol Resour 10:564-567

Francisco LV, Langston AA, Mellersh CS, Neal CL, Ostrander EA (1996) A class of highly polymorphic tetranucleotide repeats for canine genetic mapping. Mamm Genome 7:359-362

Fredholm M, Wintero AK (1995) Variation of short tandem repeats within and between species belonging to the Canidae family. Mamm Genome 6:11-18

Gachot-Neveu H, Lefevre P, Roeder JJ, Henry C, Poulle ML (2009) genetic detection of sex-biased and age-biased dispersal in a population of wild carnivore, the red fox, Vulpes vulpes. Zoolog Sci 26: $145-152$

Galov A, Sindicic M, Andreanszky T, Curkovic S, Dezdek D, Slavica A, Hartl GB, Krueger B (2014) High genetic diversity and low population structure in red foxes (Vulpes vulpes) from Croatia. Mamm Biol 79:77-80

Gloor S, Bontadina F, Hegglin D, Deplazes P, Breitenmoser U (2001) The rise of urban fox populations in Switzerland. Mamm Biol 66:155164

Griffin E (2008) Blood sport: hunting in Britain since 1066. Yale University Press, New Haven

Harris S, Morris P, Wray S, Yalden D (1995) A review of British mammals: population estimates and conservation status of British mammals other than cetaceans. Joint Nature Conservation Committee (JNCC), Peterborough, pp. 1-216

Heydon MJ, Reynolds JC (2000) Demography of rural foxes (Vulpes vulpes) in relation to cull intensity in three contrasting regions of Britain. J Zool 251:265-276

Heydon MJ, Reynolds JC, Short MJ (2000) Variation in abundance of foxes (Vulpes vulpes) between three regions of rural Britain, in relation to landscape and other variables. J Zool 251:253-264

Holmes NG, Mellersh CS, Humphreys SJ, Binns MM, Holliman A, Curtis R, Sampson J (1993) Isolation and characterization of microsatellites from the canine genome. Anim Genet 24: 289-292
Holmes NG, Dickens HF, Parker HL, Binns MM, Mellersh CS, Sampson J (1995) 18 Canine microsatellites. Anim Genet 26:132-133

Jakobsson M, Rosenberg NA (2007) CLUMPP: a cluster matching and permutation program for dealing with label switching and multimodality in analysis of population structure. Bioinformatics 23:1801-1806

Kalinowski ST, Taper ML, Marshall TC (2007) Revising how the computer program CERVUS accommodates genotyping error increases success in paternity assignment. Mol Ecol 16:1099-1106

Kyle CJ, Strobeck C (2002) Connectivity of peripheral and core populations of North American wolverines. J Mammal 83:1141-1150

Kyle CJ, Strobeck C (2003) Genetic homogeneity of Canadian mainland marten populations underscores the distinctiveness of Newfoundland pine martens (Martes americana atrata). Can J Zool 81:57-66

Learmount J, Zimmer IA, Conyers C, Boughtflower VD, Morgan CP, Smith GC (2012) A diagnostic study of Echinococcus multilocularis in red foxes (Vulpes vulpes) from Great Britain. Vet Parasitol 190: $447-453$

Lloyd HG (1980) The red fox. BT Batsford Ltd, London

MacDonald DW (1989) Running with the Fox. Harper Collins, London

MacDonald DW, Mace G, Rushton S (1998) Proposals for future monitoring of British mammals. Department of the Environment, Transport and the Regions, London

Magory Cohen T, King R, Dolev A, Boldo A, Lichter-Peled A, Bar-Gal GK (2013) Genetic characterization of populations of the golden jackal and the red fox in Israel. Conserv Genet 14:55-63

Mullins J, McDevitt AD, Kowalczyk R, Ruczyńska I, Górny M, Wójcik JM (2014) The influence of habitat structure on genetic differentiation in red fox populations in north-eastern Poland. Acta Theriologica 59:367-376

Nei M (1973) Analysis of gene diversity in subdivided populations. Proc Natl Acad Sci U S A 70:3321-3323

Oishi T, Uraguchi K, Takahashi K, Masuda R (2011) Population structures of the red fox (Vulpes vulpes) on the Hokkaido Island, Japan, revealed by microsatellite analysis. J Hered 102:38-46

Ostrander EA, Sprague GF, Rine J (1993) Identification and characterization of dinucleotide repeat ( $\mathrm{Ca}) \mathrm{N}$ markers for genetic-mapping in dog. Genomics 16:207-213

Peakall R, Smouse PE (2012) GenAlEx 6.5: genetic analysis in Excel. Population genetic software for teaching and research - an update. Bioinformatics 28:2537-2539

Pope LC, Butlin RK, Wilson GJ, Woodroffe R, Erven K, Conyers CM, Franklin T, Delahay RJ, Cheeseman CL, Burke T (2007) Genetic evidence that culling increases badger movement: implications for the spread of bovine tuberculosis. Mol Ecol 16:4919-4929

Pritchard JK, Stephens M, Donnelly P (2000) Inference of population structure using multilocus genotype data. Genetics 155:945-959

Rosenberg NA (2004) Distruct: a program for the graphical display of population structure. Mol Ecol Notes 4:137-138

Rousset F (2008) Genepop'007: a complete reimplementation of the Genepop software for Windows and Linux. Mol Ecol Resour 8: 103-106

Sambrook J, Russell DW (2001) Rapid isolation of mammalian DNA. Cold Spring Habour Laboratory, New York. http://www. molecularcloning.com/members/protocol.jsp?pronumber= 6\&chpnumber $=6$

Scott DM, Berg MJ, Tolhurst BA, Chauvenet ALM, Smith GC, Neaves K, Lochhead J, Baker PJ (2014) Changes in the distribution of red foxes (Vulpes vulpes) in urban areas in Great Britain: findings and limitations of a media-driven nationwide survey. PLoS One 9: e99059

Smith GC, Gangadharan B, Taylor Z, Laurenson MK, Bradshaw H, Hide G, Hughes JM, Dinkel A, Romig T, Craig PS (2003) Prevalence of zoonotic important parasites in the red fox (Vulpes vulpes) in Great Britain. Vet Parasitol 118:133-142 
Teacher AG, Thomas JA, Barnes I (2011) Modern and ancient red fox (Vulpes vulpes) in Europe show an unusual lack of geographical and temporal structuring, and differing responses within the carnivores to historical climatic change. BMC Evol Biol 11:214 (http://www. biomedcentral.com/1471-2148/11/214)

Wandeler A, Wachendörfer G, Förster U, Krekel H, Schale W, Müller J, Steck F (1974) Rabies in wild carnivores in central Europe I. Epidemiol Stud Zbl Veterinaermedizin B 21:735-756

Wandeler P, Funk SM, Largiader CR, Gloor S, Breitenmoser U (2003) The city-fox phenomenon: genetic consequences of a recent colonization of urban habitat. Mol Ecol 12:647656

Webbon CC, Baker PJ, Harris S (2004) Faecal density counts for monitoring changes in red fox numbers in rural Britain. J Appl Ecol 41: 768-779

Weir BS, Cockerham CC (1984) Estimating F-statistics for the analysis of population structure. Evolution 38:1358-1370

Zimmer IA, Hunter SJ, Morgan CP, Hunt KR, Smith GC, Howell M, Taylor MA (2008) Detection and surveillance for animal trichinellosis in GB. Vet Parasitol 151:233-241 